\title{
REDUCING ARCHITECTURE TO AN IMAGE
}

\author{
AGNIESZKA LEWANDOWSKA \\ Faculty of Architecture at Warsaw University of Technology, \\ Koszykowa 55, 00-659 Warszawa \\ E-mail address: ga.lewandowska@gmail.com \\ ORCID: https://orcid.org/0000-0001-6542-5948
}

\begin{abstract}
Aim. The subject of this work is reduction of architecture complexity to particular image, deprived of its context and time. The author aims to present the problem of perceiving architecture through visual experience only.

Methods. The author of the article describes the process of reduction basing on example of iconic sacred building - Church of the Light, designed by Japanese architect Tadao Ando. The analysis of all stages of transformation and reinterpretation of original complex design is conducted. The aim is to indicate how misrepresentation of design and reduction to particular image was transferred to architecture once again.

Results and Conclusion. The essential conclusion of the article is the impact and power of image culture. The author of the article indicates how contemporary world of pictures influences human perception of space and limit it to one sense - sight.

Key words: architecture, image, sacred space
\end{abstract}

\section{INTRODUCTION}

rchitecture concerns many aspects of everyday life. It is inseparably rela-
ted to each of us. We work, live and move in architecture. Elevations of
buildings, their proportions, heights, distances affect how we feel and how
we use it. The environment affects our mood, makes us want to stay in or
out of it. We perceive the world individually through the prism given by
our body and emotions. Architecture is not only streets and facades. It also
concerns the interiors of buildings in which people spend most of their lives.
Workplace, staircase or restaurant are also designed. Their walls, heights,
size of the rooms, as well as furniture, colors and fabrics create the architec-
ture that surrounds us all the time. We perceive places in which we stay thro-
ugh the prism of our body. Feelings regarding a given space are shaped by
our experience, emotions as well as by the scale of the body and senses. Sight
is the first to form our image of a given place. The perception of the space is
further supplemented with the experience of smell, hearing and touch. Quiet
- loud, warm - cold, light - dark. In this way, we experience space directly. 
However, the possibilities that the modern world opens up for us allow to explore it also in a virtual way.

Technological progress and cultural changes that took place at the turn of recent decades have had a significant impact on the perception of space. Sight, and thus visual message, has become a dominant sense by means of which we perceive events, surroundings and phenomena. Going further, cognition is often limited to what we see. Applications and programs such as google images, pinterest or instagram limit information mainly to the visual message. Descriptions under the pictures are residual and laconic. The verbal message is reduced to a few words or phrases describing the characteristics of the photo or graphic. Undeniably, the image has become the most powerful promotional tool. Its strength lies in the ability to reach every customer regardless of its location. Architecture also takes part in this fight for attention and popularity. Architecture is not only a background anymore, but it became itself an object captured through the image and framed. The essence of the building's designing process is blurred. The idea behind the project and its context is reduced to the image that the author of picture creates in its subjective way.

\section{ARCHITECTURE AND IMAGE}

Architecture is inseparably related to the image. All stages of its creation are captured graphically. The design before its construction is preceded by many stages relayed in a visual way. The idea is born through sketches, which are later translated into plans and sections. It is a way of communication between the author of the project and the investor and contractor. The architect communicates with architecture's future user by visualization. The computer-generated image of the object allows to imagine what building will look like and how it will affect the space in which will be found. Modern technology allows to create a visualization that is difficult to distinguish from a photograph. However, the same is happening the other way round. Computer programs and applications allow to modify photographs, resulting in an unrealistic visual message. Visualization is difficult to distinguish from a photo and a photo from a computer generated reality. Both the visualizations and photos also serve the promotion of the architect, his work and designed object. After the construction is fully completed, the architecture is put into use. Its image is being built by subjective reactions of users. Users who this particular image will pass on to others. The architecture is filtered through emotions and feelings of the author of the picture, then once again through the recipient of the image. It ceases to exist as a whole - as a work inseparably connected with the context, material or time. The project is dissected. It is often deprived of the environment in which is located, and cropped. The most attractive, the most interesting shots of details and particular fragments of the building are selected. In the photographs depicting architecture, people are often missing. They might "disturb" perfect picture frozen in time. Such framed architecture becomes a sculpture. It ceases 
to be experienced or used, and is transformed into a beautiful picture taken out of time and place. Buildings that become an icon are reduced to a specific shot showing precisely this iconicity - the most characteristic element, detail or shape, which ceases to be perceived as a whole. This creates the temptation to transplant a particular architecture into a new context and try to obtain the same experience of a particular building in its specific location. The sensation that evokes consists of time, place, light or climate that affect the perception of architecture, how it changes during the day, how intense the colors are, how it smells. What results in tearing the project out of its original context, with the attempt to transfer the idea and emotions that it brings?

\section{CHURCH OF THE LIGHT BY TADAO ANDO}

Architecture, which can be easily defragmented for particular images and shots, is architecture that carries distinctive emotional charge - a design behind which hide symbolism and meaning that affects its perception. Sacred buildings are just such a type of architecture. By the example of one of them, the author of the article will present the phenomenon of reducing architecture to the image.

An extremely recognizable object among sacred buildings is the Church of Light located in the small town of Ibaraki in Japan. The construction of chapel together with the Sunday school were completed in 1989. The buildings were designed by world-renowned Japanese architect Tadao Ando ${ }^{1}$. In order to understand the recognizable aesthetics of its buildings, it is necessary to present the elements that make up the whole of its architecture. Combined with each other, create a unique impression. The inseparable components of each building are: unvarnished material, expressive geometry and shaped by architect nature (El Croquis, 1996, p.348).

T. Ando's (1978) designs are formed by specific usage of walls - he sets a clear boundary between the outside world and the hidden interior. The surroundings of the building are also clearly geometrized. By means of this process, architecture marks the way to the interior of the building. Ando leaves no choice - the user must follow a clearly marked path. This way of designing is visible in Church of Light in Ibaraki, as well as in Buddhist temples in Hompokuji and Sapporo. In Japan, religions coexist (Baek, 2009, p.186). One person can be both a Catholic, a Buddhist or a Shinto follower. In Ando designs, regardless of the type of temple, similar elements that affect the shape of its architecture might be distinguished.

Ando in his designs uses one basic material - concrete. At the same time, it is a construction as well as the finishing of the façade. He uses an original, unique mixture that reflects light in a certain way (Paiva, 2017, p.122). Years

1 Tadao Ando - Japanese architect born in 1941 in Osaka. The author of more than 100 buildings. In 1995 received Pritzker Architecture Prize for "consistent and significant contributions to the built environment" (Dal Co 1996, p.1) 
of experience and experiments have made it possible to obtain material with a minimum of imperfections. His concrete is smooth, satin, thanks to which the sun's rays slip on its surface. The materials present in the design are unpainted and raw in their expression. The interior and exterior are simple, devoid of ornaments that would distract attention from what is most important - from meeting god and searching for yourself.

The last element that complements Ando's architecture is nature. Each building is determined by natural environment. However, it is not untouched nature, it is shaped by man. The space created by architect will never be found in the natural landscape (Ando, 1996, pp. 348-349). Ando uses this factor to emphasize the idea behind the building, hidden at the end of the path. He uses light, wind and water in his works, catches them into architectural frames and changing their natural meaning.

\section{RELATION OF ARCHITECTURE WITH ITS CONTEXT}

All the elements listed above can be clearly distinguished in the Church of Light in Ibaraki. The chapel is located in a small town, in a residential area where single-family houses prevail. The Church of the Light creates the complex of two buildings located on a small plot of land, elevated in relation to the street at which it is located. The chapel of the church is oriented towards the south-east. The East is the natural orientation for Christian temples, symbolizing rebirth and hope. To the main chapel leads designed path, hidden behind a bend at the end of the plot. Meandering refers to the Japanese roji paths leading to tea rooms (Paiva, 2017, p. 122). The entrance is always hidden, remote from the beginning of the road. Following the path, makes time to calm down, leave everyday life behind and prepare for the experiences waiting inside the temple.

Both buildings are simple concrete cuboids. In addition, the chapel was cut at a slight angle with a wall that marks the vestibule. The vestibule is the last link with outside world. The door leading to it and the entrance to the main hall are offset from each other, thanks to which the natural light does not enter the interior. Inside impresses what makes this building unique. On the top wall of the building, behind the altar, Ando designed a cruciform "window". The opening through the concrete wall allows the light to flow into the interior. With this architectural filter, the light is transformed into a divine element. The eastern light is white, sharp and blinding. Sunday masses take place at 10.30. The rays of the sun in the morning hours fall straight through the cross, illuminating the interior symmetrically according to its south-east orientation.

This particular image - a blinding cross built by light, has become an icon. It represents the entire complex architecture of this building and influences emotions in unusual way. This image has been deprived of its story and the path, of which culmination is hidden the symbol of the cross painted with light.

The reduction of architecture to the image, in the case of the Church of the Light, went one step further. In 2017, the exhibition dedicated to the work 
of Tadao Ando was organized at The National Art Center in Tokyo. In the museum, photoghraps, models describing the history of his architectural achievements were presented. The architect's studio was also presented in a natural scale, and the Church of Light - its most famous work - was reconstructed at the National Art Center plaza. The building deprived of its context, in which and thanks to which had been designed was transplanted to the Tokyo district. The chapel was located on a large square, surrounded by highways and skyscrapers. The concrete structure and proportions of the cuboid have been reconstructed, however the building has been oriented towards the west. The incoming light differs from the original object. The rays of western light are low and long, in warm shades of yellow, orange and red. In order to obtain a height difference, the natural hill in Ibaraki was replaced by a technical gangway. The architect himself mentions in an interview: "I desired the Church of the Light to become accessible for the general public to experience. It is a 1:1 replica of the original building and holds complete integrity to the initial design concept" (Mairs, 2017). During the three months of the exhibition, visitors had the chance to experience this iconic architecture in the way the architect allowed them. "Architecture must be experienced in person. Photographs may represent the appearance of a building, but cannot replicate human perceptions of material, scale, and light" (Mairs, 2017). This is how Ando describes the possibility of exploring his most famous building at the exhibition Endevours and experiencing the sensations that it should evoke.

\section{ARCHITECTURE IN USE}

Building a replica of such a known building and placing it in different location raises a number of questions and doubts. Is it possible to experience sacred architecture, saturated with symbolism and meaning, without the context in which it was created? The building is a frame for spiritual experiences that take place in a participant of the mass. The symbolism of the path and light is extremely clear in the original building, and its replica is deprived of these aspects. In the first case it is a temple, in the second it becomes an exhibit. The building has been stripped of its surroundings and the path that leads to it, and the most important element - the light, has been distorted. At the organized exhibition, visitors admired the building, which was created to be used. At the same time, it was deprived of its basic function, which is the use of the temple. What is left is admiring the cuboid form, its geometry, the material's perfection and the idea of cruciform window.

\section{CONCLUSIONS}

The example of the Church of the Light is unique due to the multitude of distortions it has undergone. The original architecture, rich in meaning, has been limited to the image of the cross of light - a single symbol characteri- 
zing the whole building. In the next stage, this particular image was translated into the architecture of the replica of the chapel, not complying the original assumptions. The replica was detached from religion and from the place that affected the creation of the building. Its original location influenced the formation of the complex, which consists of a chapel and a Sunday school.

In the contemporary world dominated by the image culture, there is also place for architecture. It is not only the background for the events captured in the frame, but also becomes the subject of the photograph itself. It is also shallow and deprived of the history thanks to which it was designed. Ando says about inability to reproduce feeling by pictures. Feelings which are learned through relation with architecture (Mairs, 2017). He also says about the experience of smells, sounds, textures of materials, the variability of light that accompanies it. Nevertheless, there is a constant striving to be surrounded with architecture-inspired photographs - striving to turn into reality images captured in the frame.

\section{REFERENCES}

1. Ando, T. (1996). Spatial composition and nature. Madrid: El Croquis: Tadao Ando 1983-1993, edición conjunta omnibus volume 44+58.

2. Ando, T. (1987). The wall as Territorial Delineation. The Japan Architect, 254.

3. Baek, J. (2009). Nothingness: Tadao Ando's Christian Sacred Space. Abingdon: Routledge.

4. Dal Co, F. (1996). Tadao Ando. Complete Works. Londyn: Phaidon Press Limited.

5. Mairs, J. (2017). Tadao Ando creates full-scale mock up of Church of the Light for Tokyo exhibition. Retrieved from: http:/ / dezeen.com.

6. Paiva, R. (2017). Light and Shadow. The importance of light in the Church of Sta. Maria and the Church of Light, of Siza and Ando. Retrieved from: http://cham.fcsh.unl.pt. 